\title{
Create a New Method of Santander Bank Branches
}

\author{
Ahmad Alqadi ${ }^{1}$ \\ ${ }^{1}$ Industrial Organization Engineering, University of Zaragoza, Spain; Industrial Organization Engineer in Star \\ Defence Logistics and Engineering in Madrid (SDLE, SL.), Spain \\ Correspondence: Ahmad Alqadi, Industrial Organization Engineering, University of Zaragoza, Spain; Industrial \\ Organization Engineer in Star Defence Logistics and Engineering in Madrid (SDLE, SL.), Spain. E-mail: \\ ahmadalqadi70@gmail.com
}

Received: September 27, 2021

Accepted: November 1, 2021

Online Published: January 30, 2022

doi:10.5430/ijfr.v13n1p18

URL: https://doi.org/10.5430/ijfr.v13n1p18

\begin{abstract}
This study was born from the first edition of the Santander Business Competition in 2018. The initial proposal of this work reached the final phase of the competition. It has then been developed and improved from a practical point of view. The study revolves around the launch of a Caravan that would represent Santander Bank, called SantCar, and would perform the same tasks as a conventional branch of Santander Bank with the help of a mobile application. The study explains all the tools needed to achieve the desired service. All the plans of SantCar with their respective security systems have been drawn up and a proposal has been made of what the mobile application would look like. An analysis of the current market and calculations of all the costs of launching this project are explained. In addition, a proposal is made for the initial operation of SantCar with its application in Madrid and in the towns of Aragon. In the end, it is explained where we could be in the year 2031, with all the benefits and savings obtained through the launch of this project.
\end{abstract}

Keywords: Santander Bank, Spain, SMART system, breakeven point, payback period

\section{Introduction of the Proposal}

Santander Bank was born on 15 May 1857 and is one of the most used banks in Spain. In order to help it facilitate its work tasks, this project aims to create a new method of banking posts to improve the service and earn more profit at the same time.

\subsection{Motivation and Scope}

The approach of this work was born mainly from the idea of military hospitals that operate in conflict zones around the world, which are well prepared and with all the necessary equipment. Therefore, it has been possible to invest this idea to present Santander Bank in a new way that can help its development, to demonstrate that it is the best bank at a national level, and one of the best banks of the 21 st century at a global level. Everything that would be necessary to set up this new creation has been developed, accounting for all the details that would affect this project both positively and negatively.

This bank launched the first edition of the Santander Business Competition iSeptember 2018, and that was the first motivation for the creation of this project. The first reasons for setting up this project were the following:

1-The less densely populated villages in Spain do not have the same banking services as the large cities (Figure 1). 


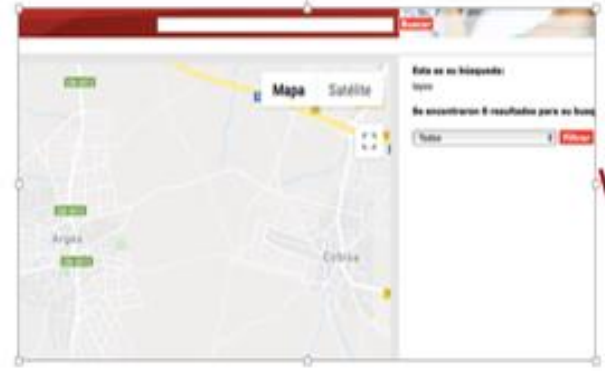

Santander branches in small towns

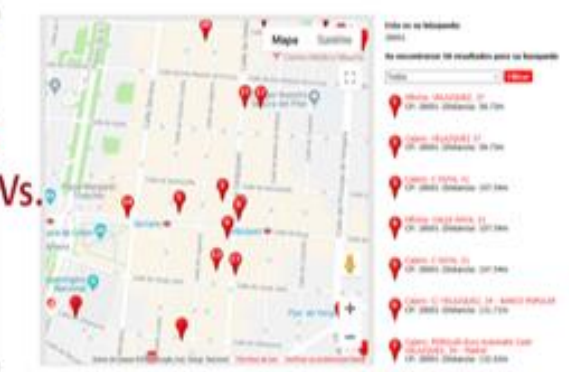

Santander branches in big cities

Figure 1. The difference of Santander branches between small towns and big cities

2-The opening hours of bank branches tend to coincide with customers' working hours, which makes it difficult to carry out the various banking procedures (Figure 2).
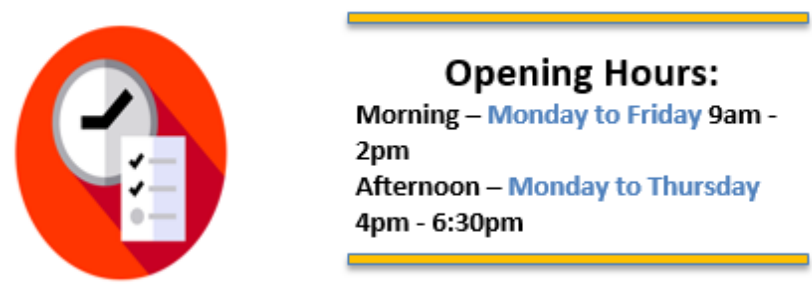

Figure 2. Opening hours of Santander Bank

This requires a study to design a mobile caravan (SantCar (Figure 3)) that provides the same services that the branches provide to customers as well as the creation of a new mobile application for the use of such caravans.

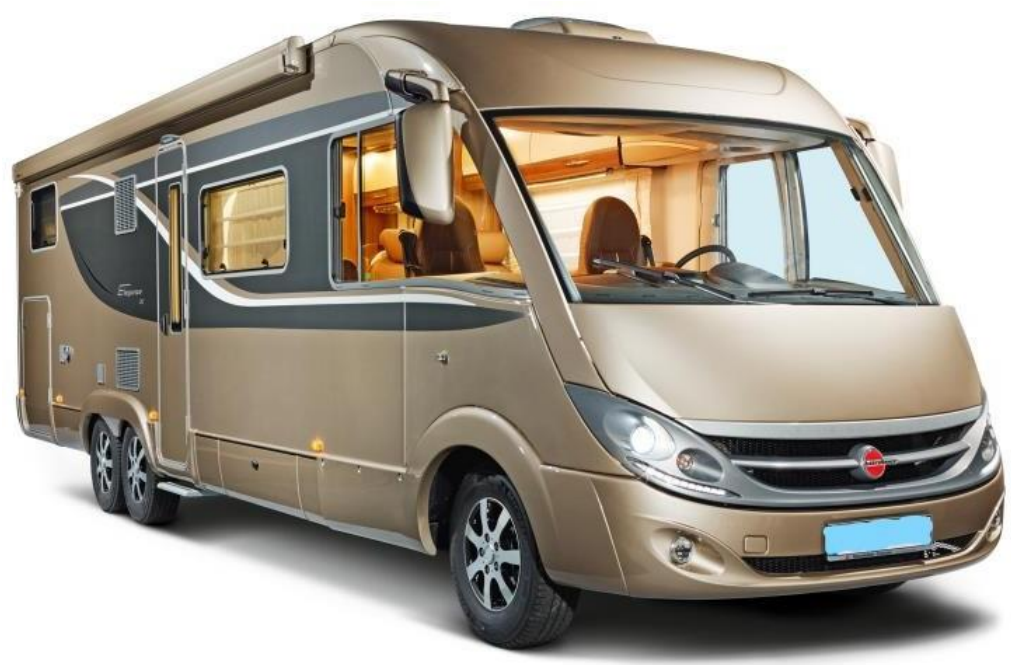

Figure 3. Future SantCar

The caravans can be of any type, and the mobile application could be designed with the help of Android Studio, since 
it is a software used to design applications for the Android system, and it could be used as a base to convert it to the IOS system because both of these systems are widely used

In addition to this, we have to explain why we are well prepared for this new project.

Our SantCar would present an entirely new way to get closer to our customers by meeting their immediate needs as well as solving problems that could arise in the long term.

To carry out this project successfully, we have created a time plan that lists the tasks to be completed, which will be presented later.

\subsection{Aim and Outreach}

The project to create SantCar aims to add two new functionalities focused on customer needs as well as to expand of Santander services throughout Spain. In order to achieve success in this work, it is necessary to define a series of objectives. These objectives are defined using the SMART system:

- $\mathrm{S}$ (Specific): It must be specific, as concrete as possible.

- M (Measurable): It must be measurable, so it must be a quantifiable goal.

- A (Achievable): It must be achievable.

- R (Reasonable): It must be realistic, within our possibilities.

- $\mathrm{T}$ (Time bound): It must be defined in time, within a timeline.

The project has been carried out with the aforementioned intention. Therefore, it is necessary to define a series of general objectives of the project that have been considered, and they are the following:

- To provide a general idea of the banking environment.

- To carry out a search for cities lacking banking services.

- To study and develop the appropriate design of the new caravan.

- To identify the risks that may arise in the future, and present a series of solutions that could be implemented in the case of these or similar risks.

- To estimate the approximate cost of this work, and the benefits it could bring in the long term.

With the help of HR, Head of Management at Santander Bank will decide what exactly they choose to consider, due to the extensive experience of their staff.

\subsection{Working Methodology}

SantCar will be Santander's service of the future. In order to achieve this goal, a number of different tasks based on consultations, studies and manuals will be needed.

Figure 4 shows the tools needed for SantCar: 


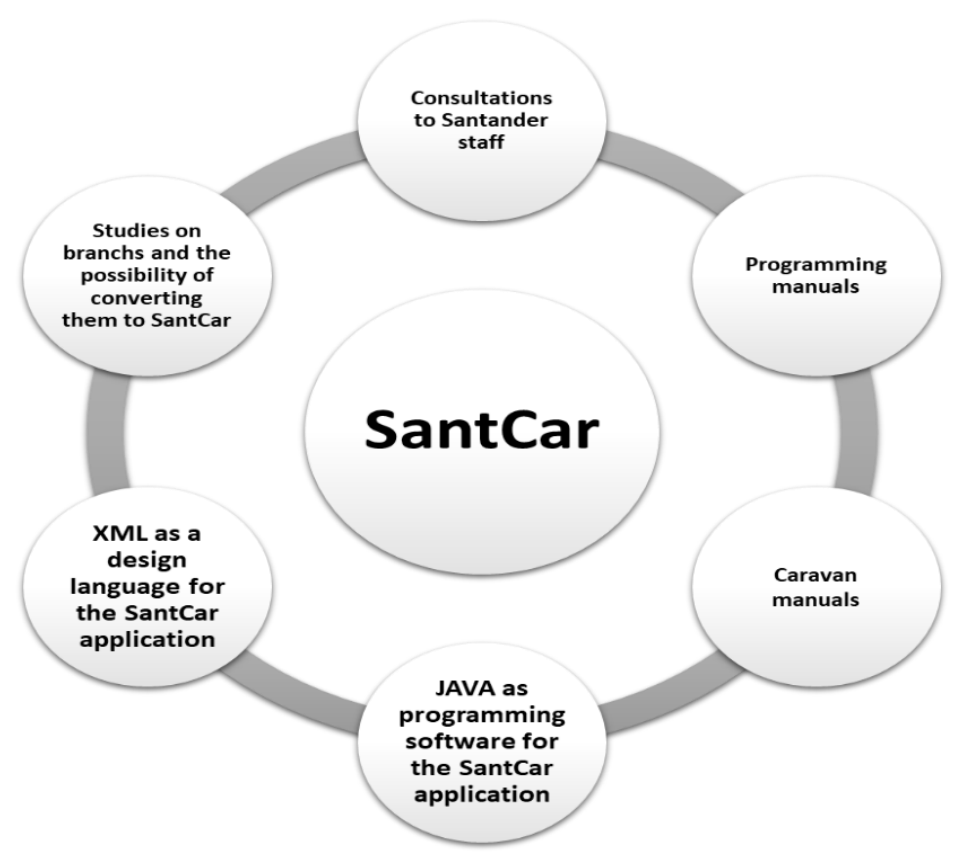

Figure 4. The necessary tools for SantCar

The following have been considered as specific objectives of the project, taking into account that some of these objectives are part of the general objectives, as they meet the requirements of both:

- To continue with the project phases without any delay.

- To create a new mobile caravan with all the services provided by the branches of Santander Bank.

- To create the possible design of the caravan.

- To create a database in JAVA and XML languages and applied to the software of Android Studio in order to have a SantCar application.

- To reduce the number of Santander branches in big cities and convert them into mobile caravans.

- To develop new training for the staff who will do this new work initially. We have to keep in mind that they will have to have sufficient banking knowledge, too, as their main task would remain banking operations performed in a new mobile environment.

- To conduct a study to determine in which cities to launch SantCar.

- To conduct a general study of customer needs to see how closely they match to what our project would create.

- To promote the platform mainly on social networks, with the help of the bank's technicians, before the official launch of SantCar to make it known to the public in advance

Once these objectives have been achieved, we can proceed with the installation of our SantCar. Subsequently, project phases are shown with their approximate time schedule: 


\begin{tabular}{|c|c|c|c|c|}
\hline Stage & Process & Starting date & Length & Finishing date \\
\hline \multirow{4}{*}{ Initial Phase } & Analyse existing problems in the market & D & 14 & $D+14$ \\
\hline & Define the current situation and the problem by making enquiries & $D+14$ & 20 & $D+34$ \\
\hline & Define the possible solution (SantCar) & $D+34$ & 40 & $D+74$ \\
\hline & Market and competency analysis & $D+34$ & 40 & $D+74$ \\
\hline \multirow{4}{*}{ Intermediate Phase } & Creating SantCar's design with its systems & $D+74$ & 20 & $D+94$ \\
\hline & Creation of the database with its corresponding application & $D+74$ & 35 & $D+109$ \\
\hline & Production of SantCar design & $D+94$ & 30 & $D+124$ \\
\hline & Publish SantCar on social media and on TV & $D+74$ & 291 & $D+365$ \\
\hline \multirow{2}{*}{ Test Phase } & Sign up for the new SantCar service & $D+124$ & 3 & $D+127$ \\
\hline & $\begin{array}{l}\text { Studies and analysis of the new service and see the impact after the } \\
\text { launch }\end{array}$ & $D+127$ & 208 & $D+335$ \\
\hline Final Phase & Final decision on launch & $D+335$ & 30 & $D+365$ \\
\hline
\end{tabular}

Figure 5. Schedule of the project

The table above shows that some actions are of different types: Finish to Start, Start to Start and some Start to Finish. A Gantt chart was made to visually show these different phases of the project and their duration.

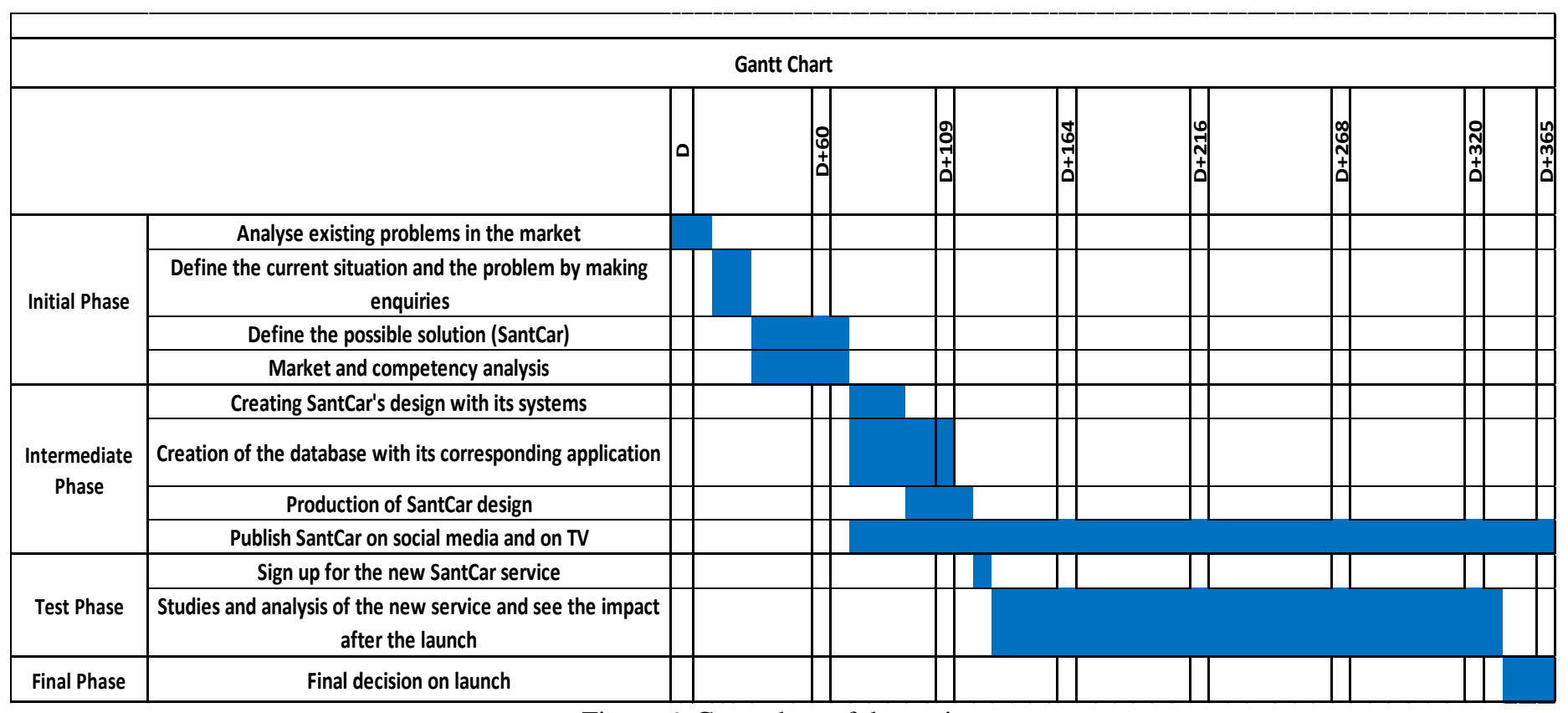

Figure 6. Gantt chart of the project

\section{Market and Competence Analysis}

Market analysis is a fundamental part of our work that allows us to know our competences in detail in the real market where we are launching our new service.

After having carried out a large analysis of the competences at a national level, we were able to observe that although there are many banks in Spain, the ones that control the market the most are the following banks: Santander Bank, BBVA, Caixabank and Sabadell Bank. 
After several consultations, we concluded that none of the aforementioned banks has a service similar to the one we are planning to launch. Therefore, Santander Bank will be a pioneer in this area.

\subsection{Project Profitability}

We have estimated this project to be profitable, achieving an increase in NPV (Net Present Value) and a decrease in RP (Payback Period). That is because what we are going to achieve by launching this project would be the following:

1-Small towns:

- Gaining customers.

- Solving the problem of lack of branches.

\section{2-Big cities:}

- Increasing customer satisfaction.

- Eliminating unnecessary branches.

- Increasing cash flow.

- Increasing time availability.

\subsection{Executive Summary}

This is the general description of the complete business plan. As mentioned at the beginning of the article, different things have to be taken in consideration:

1-The style of the caravan: in this case it will be a 5.5 meter * 2.2 meter caravan. The caravan will be the new mobile Mini-Branch, with the color red representing our bank. The design and mode of operation of the caravan will be presented later.

2-Name: we have decided to name our caravan SantCar. This name can be changed by the request of the bank executives. It has been chosen after several consultations, for it not to coincide with possible names used internationally.

3-Location: The caravan will be mobile and will have the necessary permits to be able to park in any area, like the new electric cars that can be rented on the streets.

\subsection{Market Analysis}

This is the marketing strategy we are planning to use for our new service. It contains the following data:

- The target: to whom we are going to present our product. As this has already been mentioned above, we will not go over it.

- Why customers will prefer to use our new service: we offer access to remote villages that suffer from a lack of services, especially when it comes to banking. We also offer our service in big cities, where employees find it difficult to access a bank branch in person. Therefore, we can go to a location that a customer prefers, make the required arrangements, and finish everything faster than in a conventional branch. All of this will be explained in more detail later.

- The competition: these are the banks we have at national level, since during the test phase we will only launch this project in Spain. And as mentioned above, national banks do not have any similar service.

- How to promote SantCar: Santander Bank will start promoting this new service during the set-up phase, so when we launch it our customers will have had access to the instructions on how to access it.

\subsection{Commercial Operation}

The creation of the caravan would require the design and architecture of the caravan by a team of mechanical engineers as well as computer engineers to build the network that the caravan will use to carry out operations.

After it is assembled, a series of tests will be performed to make sure that the caravan can carry out its operations in any physical space. In other words, it will start by providing support to offices that are already open in the event of any problem or conflict with the network.

Simultaneously, a database to be used by the caravan together an application that will allow contact between the user 
and the caravan will be developed

Once both products have been set up, a test phase will start in which a limited number of appointments per municipality will be granted and the demand for this service will be measured

This product will be available to demographics of all ages, because even if one sees the caravan but does not have an appointment, due to the database it carries, it can also take appointments on the spot for the different procedures, embracing the older public.

The main things to keep in mind are the following:

- Products and services: please see above.

- The number of employees required: please see in detail below:

1-Driver: someone with extensive experience as moving around a lot of places during working hours will be required

2-SantCar Manager: someone to make sure everything works well within SantCar and look after the employees. $\mathrm{He} / \mathrm{she}$ will be in charge of taking care of the VIP clients of our Santander Bank.

3-Two managers: two people to facilitate customer service. There will be one manager for customers who can access SantCar and who are registered in the Santander Bank's database, while the other manager will attend to customers through a SantCar window. The distribution of the managers will be explained in section 4.1. "Sketch of SantCar".

4-Security personnel: to protect the interior of SantCar during working hours.

The network of our SantCar will be connected through a VPN with the Financial City Santander Bank, so it is not necessary to have a network operator within SantCar, and in the case of an incident, SantCar will go to a branch that has a network operator to solve the problem.

- The benefits of that implementing our project will bring to customers: the reasons for launching SantCar are the following:

1-To reduce the inconvenience that customers in villages experience due to the lack of banking services.

2-To facilitate access to branches from any point in large cities, as long as it benefits our customers.

Now, we break down the business model into key needs and eliminate or change elements. The business plan is an indispensable tool to get off to a good start. And although it does not guarantee immediate success, there are points that would help us:

1-Our business will be an opportunity to turn a bank into a mobile branch to solve the mobility problems of our customers. Therefore, we need to have the necessary certificates from the town hall of each municipality to facilitate the mobility issue without any inconveniences.

2-We have to keep in mind from the beginning that SantCar is a business that needs a plan that reflects all the full costs and major risks with ways to overcome them in the future. Therefore, in this proposal we will reflect all these points.

- With the business plan for opening a SantCar you can achieve four things:

1-Show the bank or a potential investor that you have a clear and concise plan for launching this new business into operation. But as our business is for a bank itself, this step is not necessary if the executives decide to go ahead with this project.

2-Have a contingency plan for problems that may arise.

3-The business plan forces you to know all parts of SantCar, as well as your competition in the local market.

4-With the business plan you can better prepare yourself to handle problems like licenses, health codes or tax laws, etc, that change depending on the country you are in.

\subsection{Management and Ownership}

Santander Bank team will decide which manager will be in charge of this new project. Human Resources will be in charge of carrying out a study of what else could benefit us after the launch of this new service.

The management of the project consists of the following:

- Training courses for employees: SantCar will be a big move from having banks branches fixed to turning them into mobile ones. There is a risk that the employees might not be able to successfully adapt to this new environment. Therefore, the bank will organize training courses for the initial team of employees who will work inside SantCar. 
- Daily reports of banking transactions made by SantCar, comparing them with those made by conventional branches.

- Monthly reports on the profits that would be made in the future.

- Commission a team from the Financial City (Santander Group) to be in charge of developing this project.

\section{Initial Business Proposal}

This project was initially accompanied by another project that consisted bringing together two famous platforms: Amazon and Santander Bank. However, in the end it has been decided to carry out each project separately in order to achieve the highest possible performance, and to have a more detailed study to facilitate the installation of these new services in the banking environment.

\subsection{Current Situation}

A study has been carried out with the help of the Santander Bank's WEB page to find out the situation of the remote villages in terms of banking services. According to the data, many villages suffer from a a lack of such services, for example, in Quinto/Zaragoza, Santander Bank does not have any office, and the nearest one is $7.498 \mathrm{~km}$ away from the village of Quinto.

That applies to many other villages, for example, Zugarramurdi (village in Navarra), the nearest branch is $11.315 \mathrm{~km}$ away from the village.

On the other hand, a study has been carried out in the big cities, and it could be observed that there are too many branches, which means unnecessary expenses that could be reduced. We will now present the study carried out in the capital of Spain, Madrid, at its very center, Puerta del Sol:

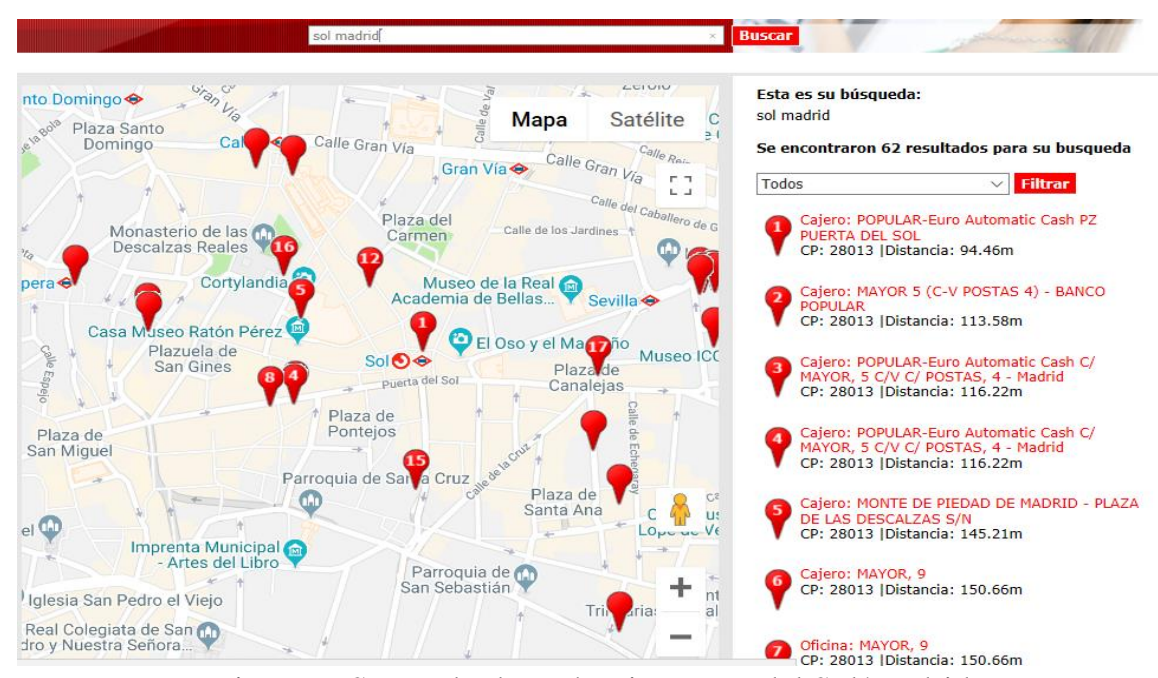

Figure 7. Santander branches in Puerta del Sol/Madrid

Within a radius of 300 meters - which is an area that can be reached by foot without any problems by people without mobility issues - in the area of Puerta del Sol, there are more than 20 ATMs and 4 branches.

\subsection{Vision for the Future}

Using the above mentioned data, it has been decided, as a start, to launch two SantCars during the test phase: one for villages and one for big cities. Their distribution will be as follows:

- A SantCar in Madrid: this SantCar will be mobile and reachable at the required locations of each user and during the booking time requested by the user. During waiting and non-booking hours, SantCar will be in the central Madrid area, Puerta del Sol, as there are always a lot of people in that area.

- A SantCar in the villages of Aragon: we will launch a SantCar that will serve the villages of Quinto, Gelsa, Alforque, Alborge, Velilla, Sástago and Cinco Olivas. People will have access to this service in the center of the village and during the hours indicated by SantCar on its mobile app. The schedule of times and locations will made through the managers and will be published in the app a week before each date. 
Because of the launching of SantCar in one of the biggest cities, we will temporarily close, the following branches:

- OFICINA CL ARENAL, 19.

- OFICINA PZ DEL CALLAO, 1.

This closure will help us to produce savings that will be described in the following sections.

\subsection{How It Works}

The cities and towns mentioned above will only have access to the service during the test phase.

SantCar will have a mobile application developed by our programmers at Santander Bank, and everyone will have an access to it, which will be explained later.

There will be a difference in the way it works between towns and cities.

\subsubsection{Villages}

The SantCar service in the villages consists of a rotation service between the villages so that Santander Bank will decide the timetable, or in other words where and when SantCar will be in each of the villages mentioned, in order to access as many users as possible.

The following is a proposal for the first operation of the above-mentioned towns for a week:

\begin{tabular}{|c|c|c|c|c|c|c|c|c|}
\hline & & & & \multicolumn{5}{|c|}{ SantCar timetable } \\
\hline & Direction & $\begin{array}{c}\text { Movement } \\
\text { duration }\end{array}$ & $\begin{array}{l}\text { SantCar } \\
\text { Location }\end{array}$ & Monday & Tuesday & Wednesday & Thursday & Friday \\
\hline Quinto & Starting point & & \multirow{7}{*}{ 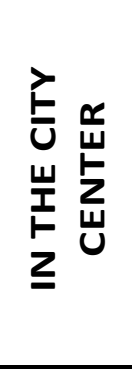 } & 09h-10h & $4: 45 h-5: 45 h$ & $4: 45 h-5: 45 h$ & 3:30h-4:30h & $1 h-2 h$ \\
\hline Gelsa & Quinto - Gelsa & 8 mins & & 10:15h-11:15h & 3:30h-4:30h & 09h-10h & 4:45h-5:45h & $2: 15 h-3: 15 h$ \\
\hline Velilla de Ebro & Gelsa - Velilla de Ebro & 7 mins & & 11:30h-12:30h & 2:15h-3:15h & 10:15h-11:15h & $09 \mathrm{~h}-10 \mathrm{~h}$ & $3: 30 h-4: 30 h$ \\
\hline Alforque & Velilla de Ebro - Alforque & $24 \operatorname{mins}$ & & $1 \mathrm{~h}-2 \mathrm{~h}$ & $1 \mathrm{~h}-2 \mathrm{~h}$ & 11:30h-12:30h & 10:15h-11:15h & 4:45h-5:45h \\
\hline Alborge & Alforque - Alborge & 6 mins & & $2: 15 h-3: 15 h$ & 11:30h-12:30h & $1 \mathrm{~h}-2 \mathrm{~h}$ & 11:30h-12:30h & $09 \mathrm{~h}-10 \mathrm{~h}$ \\
\hline Sástago & Alborge - Sástago & 7 mins & & $3: 30 \mathrm{~h}-4: 30 \mathrm{~h}$ & 10:15h-11:15h & $2: 15 h-3: 15 h$ & $1 \mathrm{~h}-2 \mathrm{~h}$ & $10: 15 h-11: 15 h$ \\
\hline Cinco Olivas & Sástago - Cinco Olivas & 8 mins & & 4:45h-5:45h & 09h-10h & 3:30h-4:30h & 2:15h-3:15h & 11:30h-12:30h \\
\hline Quinto & Going back to Quinto & $18 \mathrm{~min}$ & & & & & & \\
\hline
\end{tabular}

Figure 8. SantCar schedule in Aragon

\subsubsection{Cities}

The mode of operation within big cities would be most similar to the mobile application UBER. Customers will $\log$ into the app with their details and choose date, location and service required.

The app will confirm the appointment and send them an email with the details of the appointment.

On the day of the appointment, SantCar will go to the location previously indicated by the customer and make the required arrangements as quickly and efficiently as possible.

\subsection{Make or Buy}

Our project consists of many tasks, so we need to save as much work as possible in order not to incur unnecessary costs. Therefore, the launch of SantCar in the future will depend on the following tasks: if it has been decided whether to make or to buy:

- The SantCar caravan:

1-The design of all the systems: all the systems of the caravan are already done, so this task would be MAKE.

2-The design of the caravan: this task is also done, so it would be MAKE.

3-The caravan itself: as Santander Group does not have a caravan factory, we would then pass our designs to a caravan factory and then purchase from them, so this task would be BUY. 
- SantCar's mobile application: Santander has a Mobile-Application team, so this task would not have additional costs, which is why it would be MAKE.

\subsection{SantCar Cost}

In this section the costs necessary for the launch and operation of SantCar will be explained. This part of the project can be reflected in five main points:

\subsubsection{Cost of the SantCar Camper-Van}

This cost is spread over four points:

- Cost of the interior design with the necessary security systems: this cost is null because it is already done and is explained in the following section (SantCar Design).

- Cost of the caravan itself: as the Santander Group does not have a caravan factory, a search was carried out and it was found that a caravan of similar dimensions to the one we are looking for costs around 52,400 euros.

- Cost of furniture, computers and network: SantCar does not require a high cost of furniture, so a total cost of 8,000 euros has been estimated.

- Cost of security systems: a Saudi Arabian company that carries out security system installation projects was contacted and it gave us the price of 12,823.45 euros. This cost includes the system and its installation inside the caravan. This cost was divided into the following:

1-Security system and control access system: 2,282.77 euros.

2-Camera control system: 9,792.63 euros.

3-Fire alarm system: 748.05 euros.

\subsubsection{SantCar Application Cost}

This cost is null as the Santander Group has a group of mobile application programmers.

\subsubsection{Cost of Publicity}

As it will be explained later, SantCar requires a pre-launch publicity. Santander has a Social Media group who will be able to take over this task. However, a total of 5,000euros will be reserved for the publicity of SantCar on TV.

\subsubsection{Maintenance Costs}

SantCar will require ongoing maintenance to keep the service running smoothly. This cost will vary but around 200 euros per month will be set aside for this task. At the same time, SantCar will need fuel for its movement. If we calculate that a day makes about 150 kilometers, we will need about 20 euros per day of fuel, which is equivalent to 420 euros per month (excluding Saturdays and Sundays as they are public holidays).

\subsubsection{Total Cost}

Calculating all of the above, this cost can be divided into three main parts:

- Launch cost: this is the cost we need to launch SantCar on the market, and this would be the total of the costs mentioned above excluding the maintenance cost and the cost of publicity. In total, this cost would be 73,223.45 euros for each SantCar we want to launch on the market.

- Cost of publishing SantCar: it is a one-time cost of 5,000 euros.

- Maintenance cost: the cost of operation of SantCar, and it would be 620 euros per month.

To sum up the data above, during the test phase and its operation during the first month this project would cost us 152,686.9 euros (two SantCars, their maintenance during the first month and publicity costs).

\subsection{SantCar Publicity}

In order to advertise quickly and efficiently, the marketing and social media team of Santander Bank will be in charge of announcing the new SantCar functionality. TV commercials can be used as a means for customers and future customers to find out about the current situation and the new service. The application has to be downloadable on mobile phones to make it easy to use and to gain the interest of the user, so that he/she is interested in participating in our survey. Therefore, we will extend the marketing campaign by sharing the application to social networks such as Twitter, Facebook, Instagram and LinkedIn, so that young people feel close to SantCar and can make use of it when they need it, as we also want to get closer to the young population (so they feel encouraged to apply for a Santander scholarship or to open their Openbank account). 


\section{SantCar Design}

- The interior design of SantCar has been made with the following things in mind:

- To be a space that is small and comfortable at the same time.

- To provide a waiting space for customers.

- To have a toilet, as the employees will be inside the caravan for many hours.

- To have a generator in case something goes wrong during operation.

- Design an Access Control System.

- Design a Close Circuit TV (CCTV) System.

- Make a Security System design.

- Make a Fire System design.

In the following section the above-mentioned designs will be presented in a way that will be understood byany engineer.

\subsection{Sketch of SantCar}

SantCar will measure 5.5 meters * 2.22 meters (excluding the driving area). It shall be made of a hard metal (e.g. H13) as it is important to discourage any attempt of armed attacks.

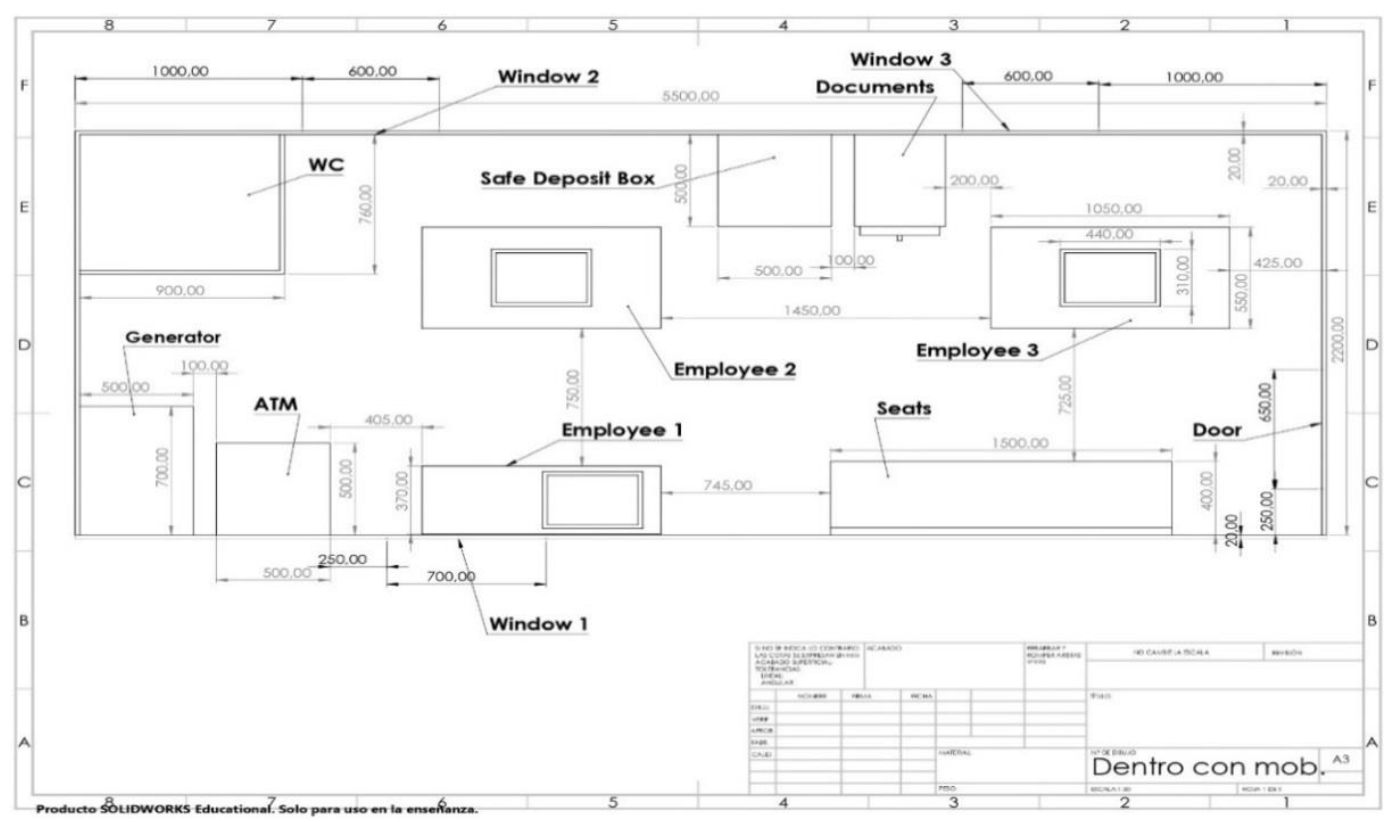

Figure 9. Sketch of SantCar

\subsection{The Interior of SantCar}

Within SantCar there will be 3 employees. Employee number 1 would be in charge of serving customers who are not registered in the Santander Bank database through window number 1. Employee number 2 is the head of SantCar and in charge of attending to the VIP customers of our SantCar. Employee number 3 would be in charge of attending to the clients who are registered in the bank's database, and will have access to the interior of SantCar. Next to the SantCar manager, there will be the safe deposit box. 


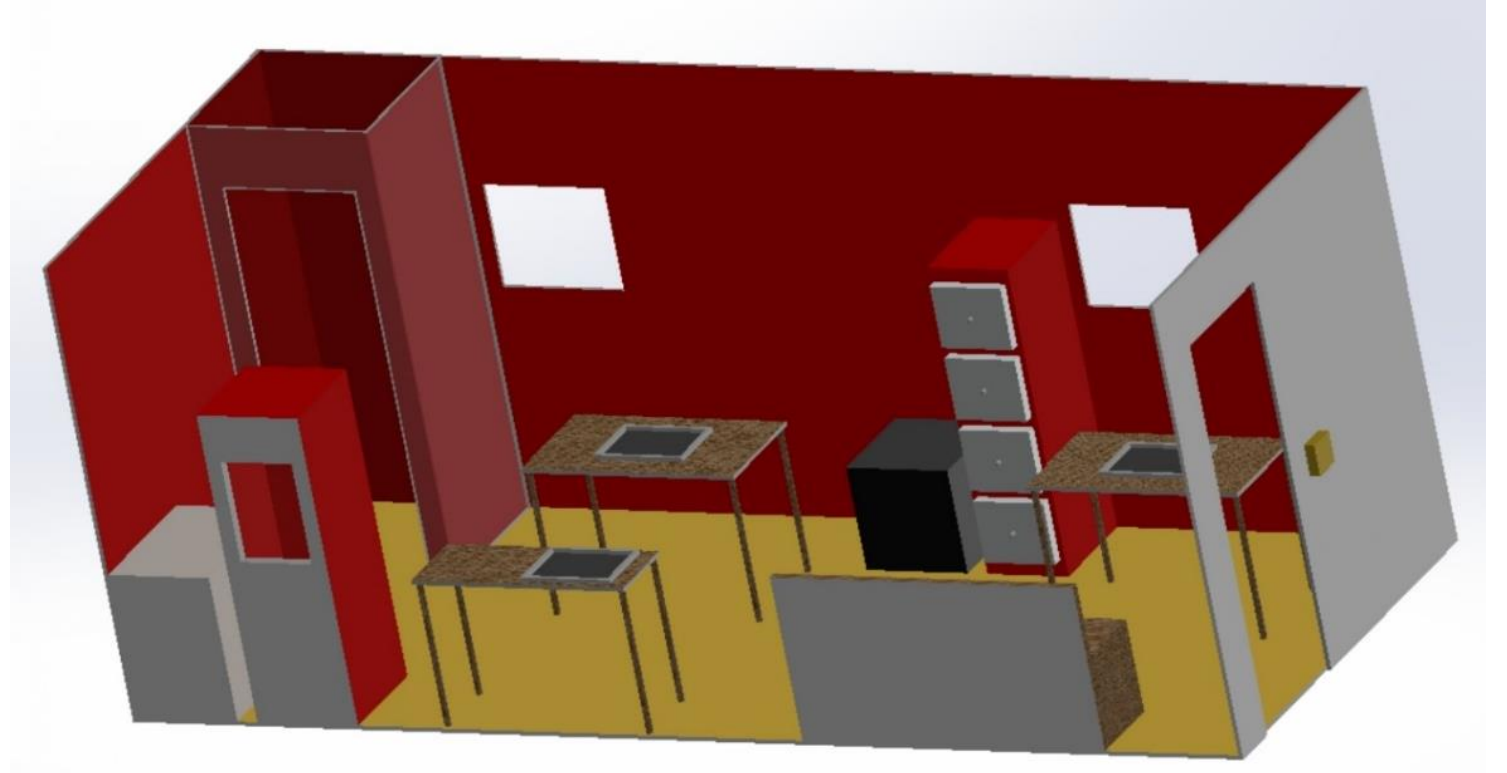

Figure 10. Interior of SantCar

\subsection{Access Control System}

This system has four main parts to facilitate access and exit from SantCar:

- Access Card Reader: it is outside SantCar. It would facilitate the access inside SantCar for the employees and the clients registered in the database.

- When an employee uses their card, the system will enable their access. When a customer uses their card, the system will first check if this registration is within the working hours, also that there are employees at SantCar to attend them, and then provide access.

- DS-Door Strike: this is the door lock.

- Exit Button: this is next to the door on the inside of SantCar. It is a button that, when pressed, allows you to exit from SantCar.

- Door Release Glass: it is also next to the door on the inside, and you would have to break its case and press it in case of an emergency. 


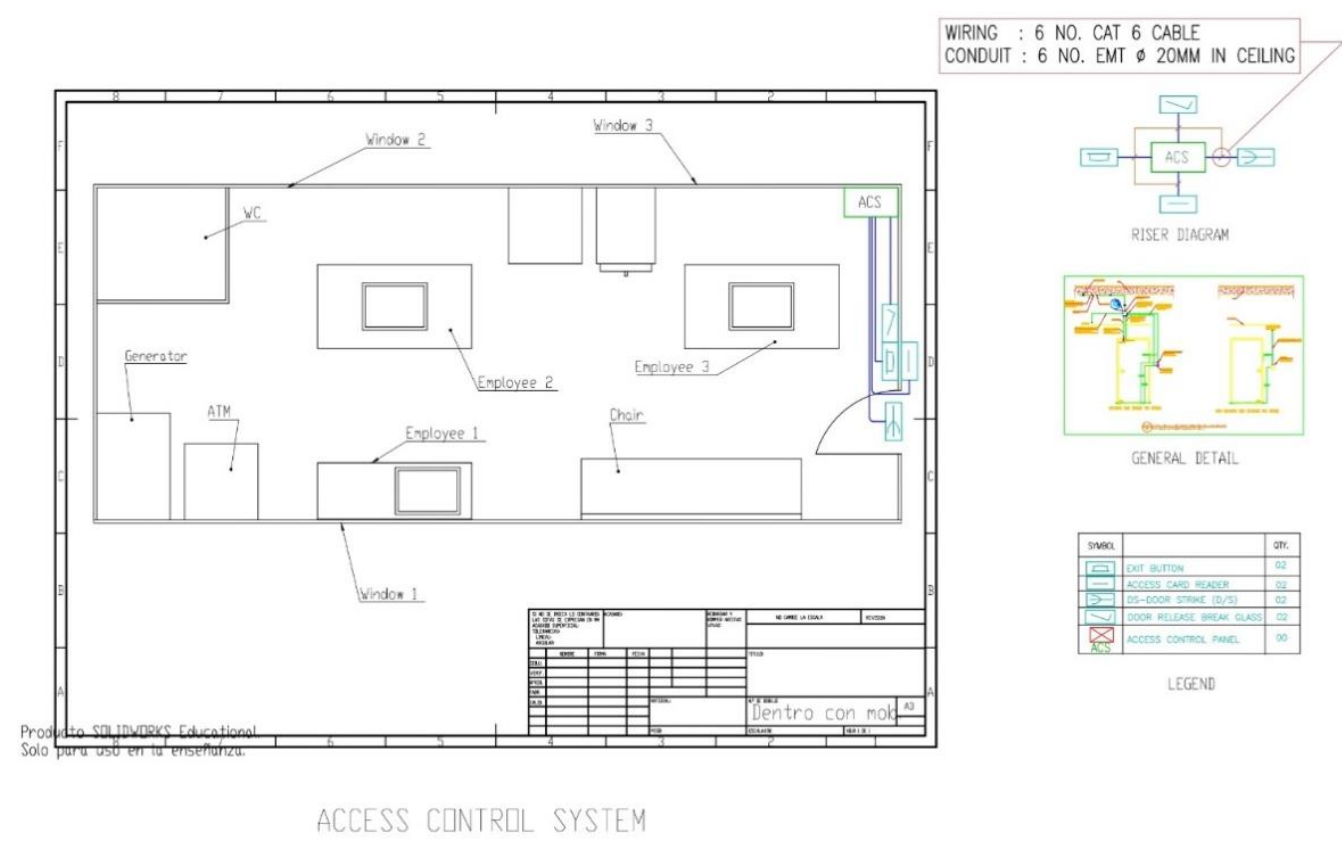

Figure 11. Access Control System of SantCar

\subsection{Security System}

The security system in any bank is very important to protect us from any incident or attempted robbery. This system in SantCar has the following:

- Motion Detector: there will be two in the middle of SantCar. This system is activated during the hours of NOT being inside SantCar. This system activates the alarm if it detects any movement inside SantCar.

- Seismic Detector: there will be four distributed on each wall of SantCar and one in the ATM. These detectors activate the alarm on the outside and inside in the case of any attempt to move, break or break into SantCar.

- Fold-Up Push: there will be three of them distributed on the desks of our employees. Pressing one of them activates the alarm and sends an alert to the police. This would be used in the case of an attempted attack on SantCar.

- Security Keypad: in case of any of the alarms are activated due to a system failure, one of our employees will be able to deactivate it through this box. 


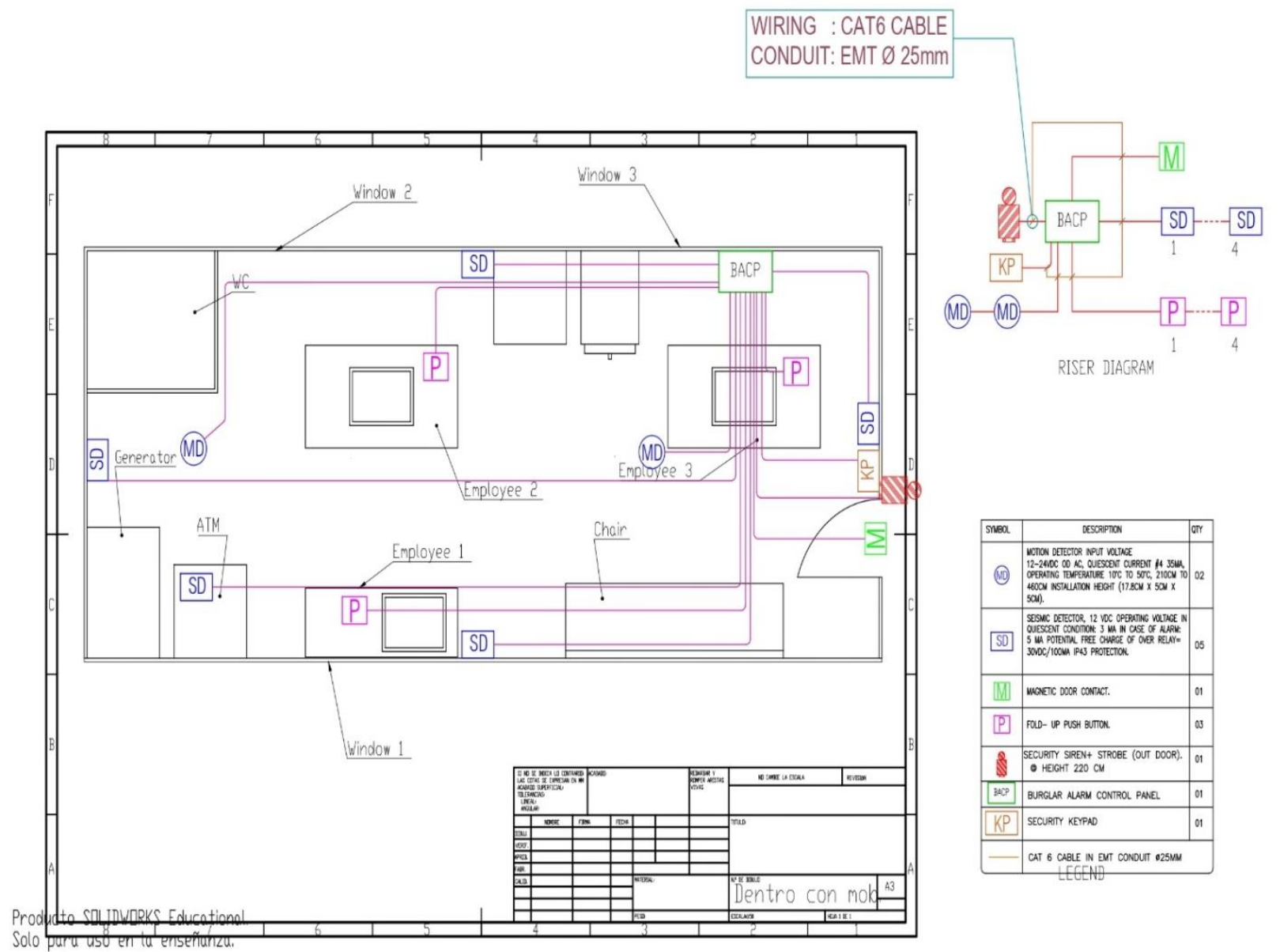

\section{SECURITY SYSTEM}

Figure 12. Security System of SantCar

\subsection{Fire-Alarm System}

The fire system is a universal and necessary system in any entity. Therefore, SantCar will also have such a system: it will be activated in case of fire inside SantCar. This system also activates the siren outside SantCar in case of a fire without people inside. 


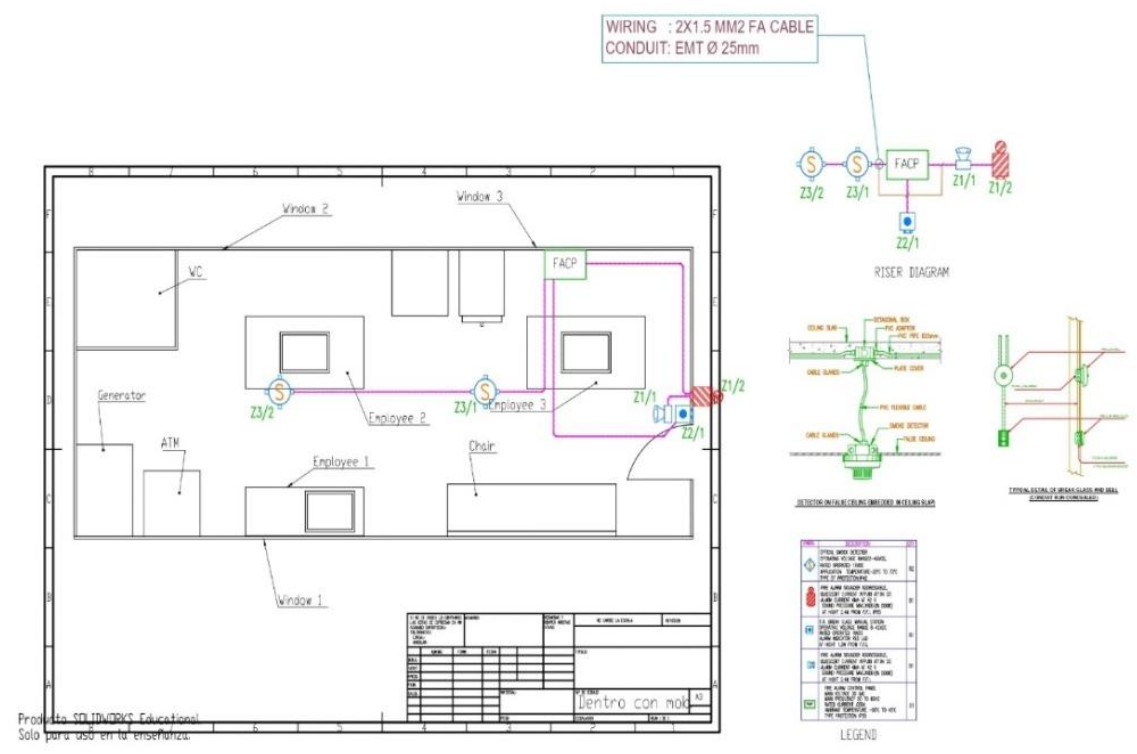

FIRE ALARM SYSTEM

Figure 13. Fire-Alarm System of SantCar

\subsection{Close Circuit TV (CCTV) System}

This is the system that monitors our SantCar from outside and inside at all times. The cameras would be IP (Information Protocol) and of high quality. The system will be connected to NVR (Network Video Record). The cameras will have a very high FPS (Frame per Moment), as the banking environment is important and requires to record all the moments inside.

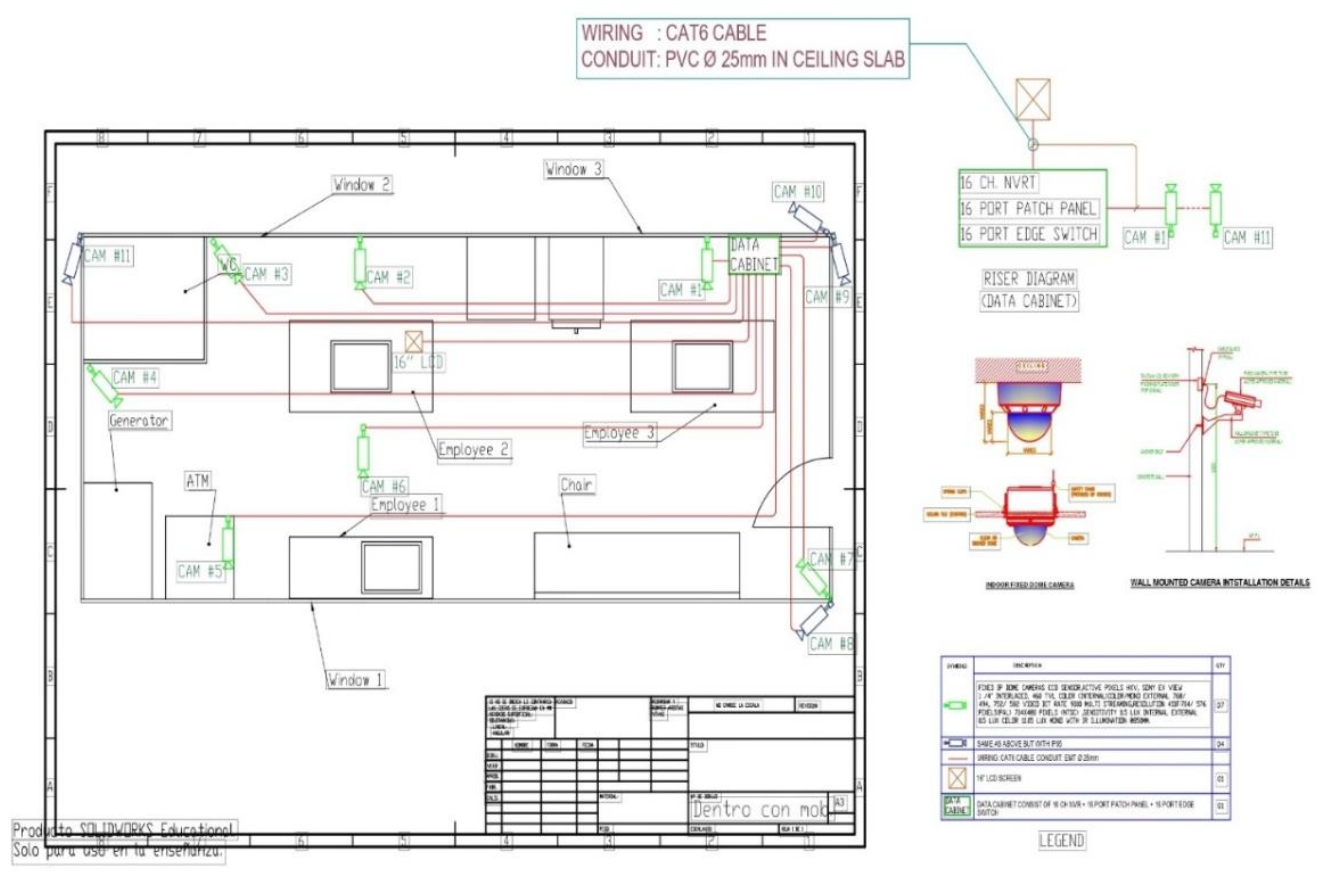

\section{CCTV SYSTEM}

Figure 14. Close Circuit TV (CCTV) System of SantCar 


\section{SantCar Application}

SantCar will consist of a mobile application for IOS and Android systems as they are very widely used. The application will be user-friendly

SantCar will have the following screens:

\subsection{Welcome Screen}

On this screen you will see the welcome message. Both Santander Bank and non-Santander Bank users will be able to use this application.

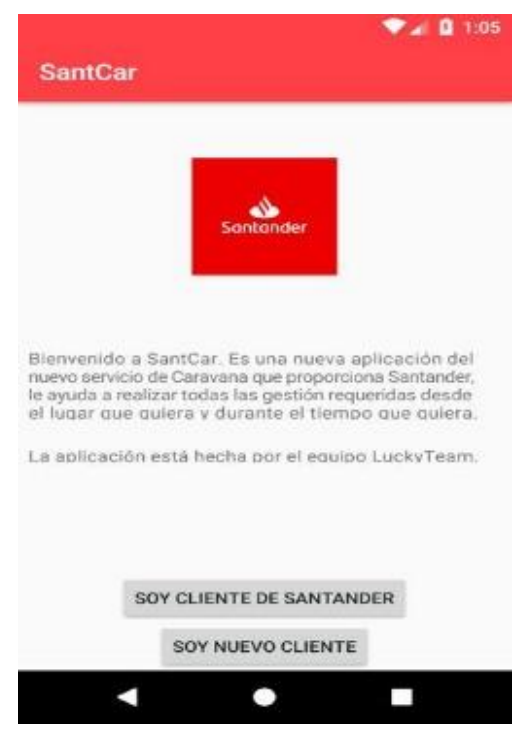

Figure 15. Welcome screen of SantCar application

\subsection{We Are From Santander}

If the user clicks on the option "I AM A SANTANDER CUSTOMER/SOY CLIENTE DE SANTANDER", a screen will appear asking to enter data, which is always required when using the regular Santander Bank application.

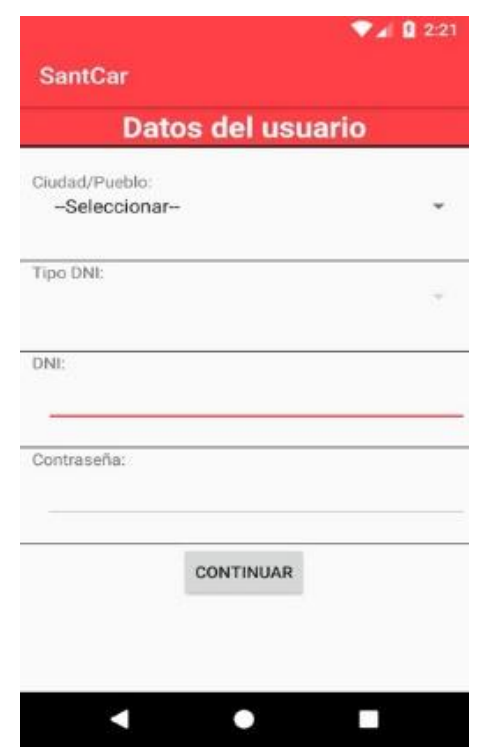

Figure 16. Santander customer screen of SantCar application 
On this screen, we can see that the customer must enter the name of their town or city. Then, if the customer has this service in their town or city, the following screen will appear, so that they can enter their details and book an appointment.
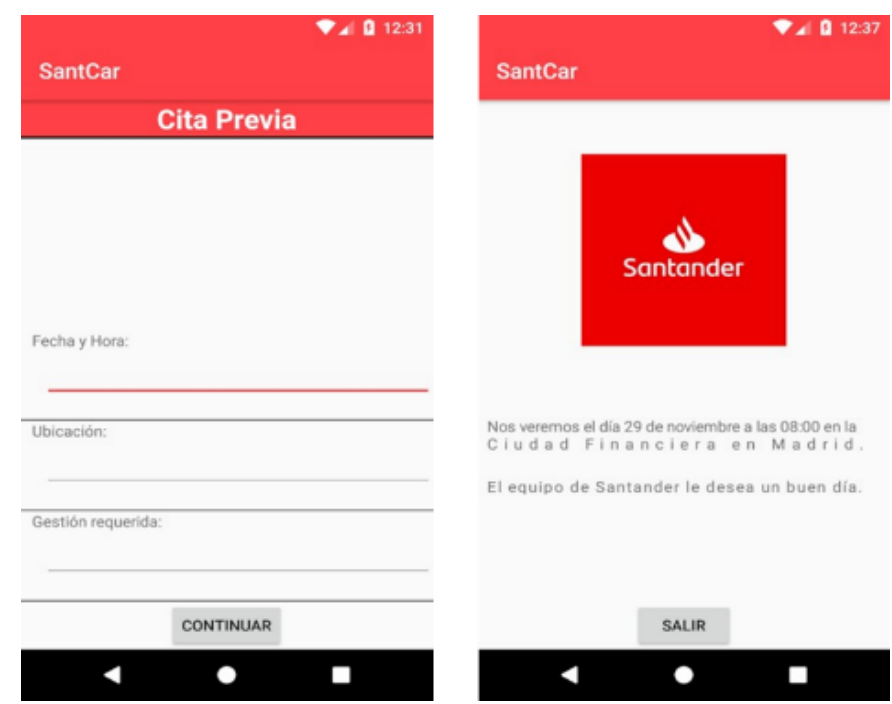

Figure 17. Booking an appointment screen of SantCar application

After entering your details, the application will confirm the customer's appointment with the desired location if they live in a big city.

If a customer is from a town, SantCar Application will indicate the time and location where it will be in the desired town.

\subsection{We Are Not From Santander}

If the user clicks on the option "I AM A NEW CUSTOMER/SOY CLIENTE NUEVO", they will then be presented with a screen with the details they need to enter, and a verification message will be sent to their mobile number. Then, they will be able to use the application as if you were from Santander.

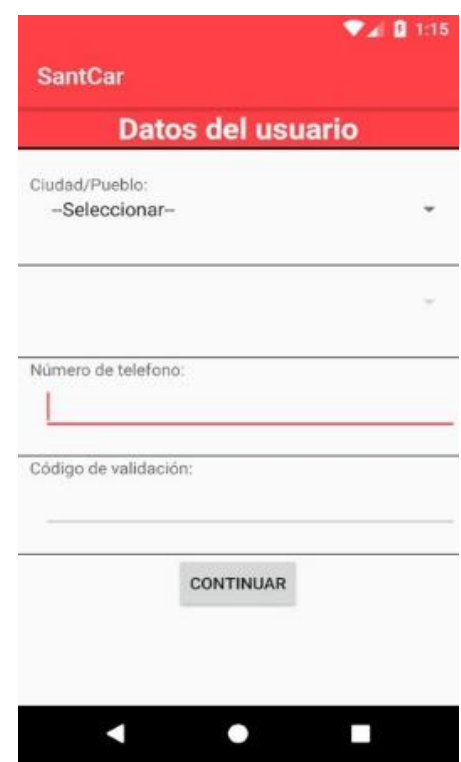

Figure 18. Non-Santander customer screen of SantCar application 


\subsection{We Do Not Have Santcar}

If a user chooses a city or town, and we do not have the SantCar service, then a user survey will be launched to see if they are interested in having this new service in their city/town.

Then, Santander Bank will do some analysis (during the test phase) and will decide the new locations of the new SantCars to be launched.

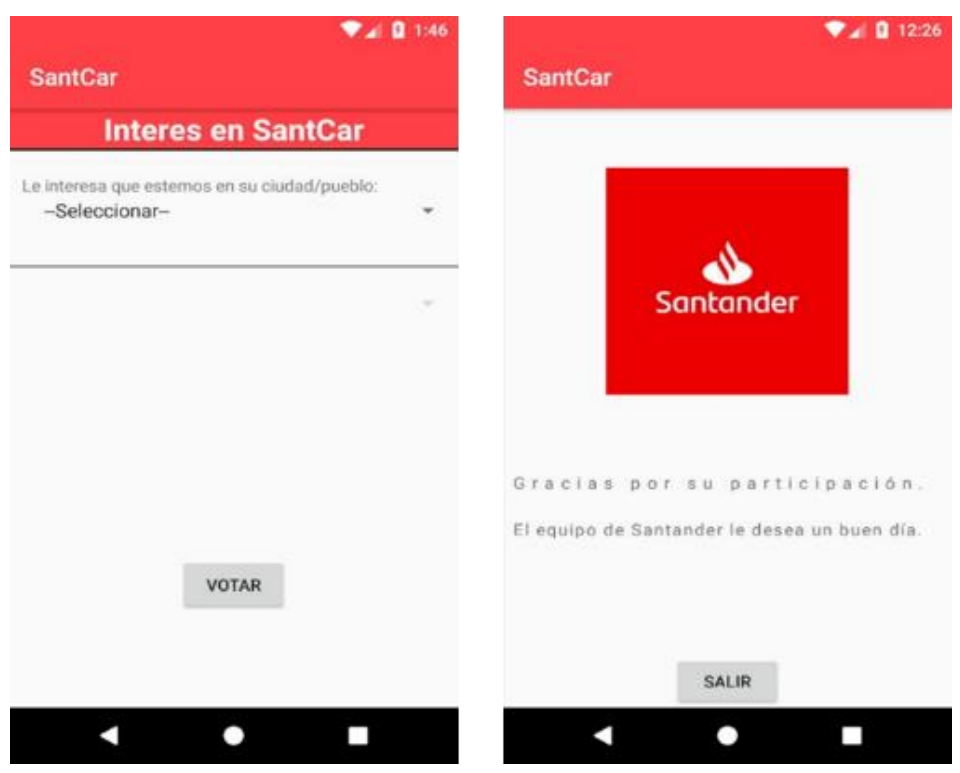

Figure 19. Interested in SantCar screen of SantCar application

\section{Risks and Solutions}

The SantCar service is a new service with no previous equivalent. Therefore, certain risks must be taken in consideration to facilitate the development of this new project.

\subsection{Robbery of SantCar}

SantCar has a high security system. And as mentioned before, everyone who can access SantCar from the inside has to be registered in the database. Hence, if someone wanted to rob a SantCar, apart from having emergency systems as mentioned above, our employees could let the robber leave without having any risk as we have registered this visit in our system.

\subsection{Loss of Material}

As SantCar is a mobile caravan and consists of a very small space, there is risk of losing important documents and materials. Therefore, at the end of each day, the driver would leave all the material at a branch of Santander Group's choice, depending on SantCar's location.

\subsection{Stealing SantCar}

It has been mentioned above that SantCar has the Motion Detector System and Seismic Detector System. This means any attempt to break or move SantCar will activate the alarm. Also, the drivers will park the SantCars at the end of each day in a private and secure car park of Santander Bank.

\subsection{Customer Satisfaction}

The goal of this project is to satisfy our customers. To do that, a survey of 12,841 people was completed in order to evaluate and assess the level of acceptance that SantCar will have when it is launched. Also, continuous studies will be made when SantCar starts operating in order to continuously improve and develop our service and keep it always adjusted to the needs of our customers, keeping their satisfaction very high.

\subsubsection{SantCar Pre-Launch Survey}

The survey consisted of the following questions: 
1-Are you a customer of Santander Bank?
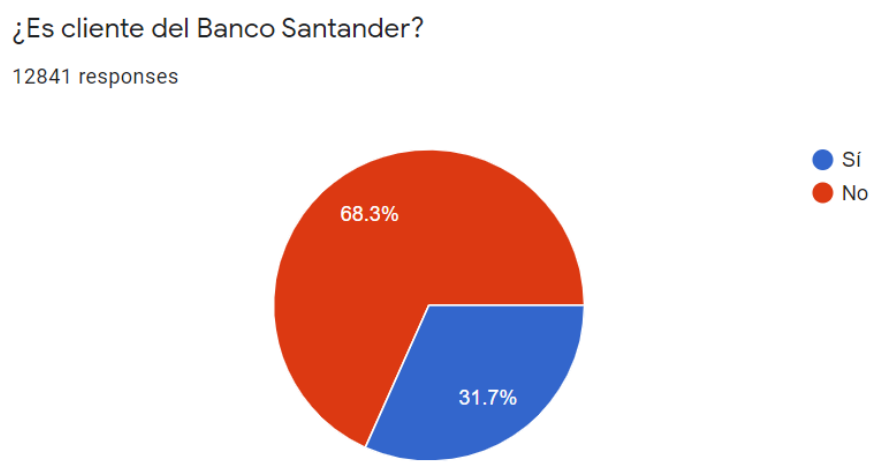

Figure 20. First question of the survey

Most of those who took the survey came from other banks. So, by launching our new service, we will have the advantage of adding new customers to the Santander Family, thus increasing our bank's cash flow.

2-Do you live in small town or in big city?

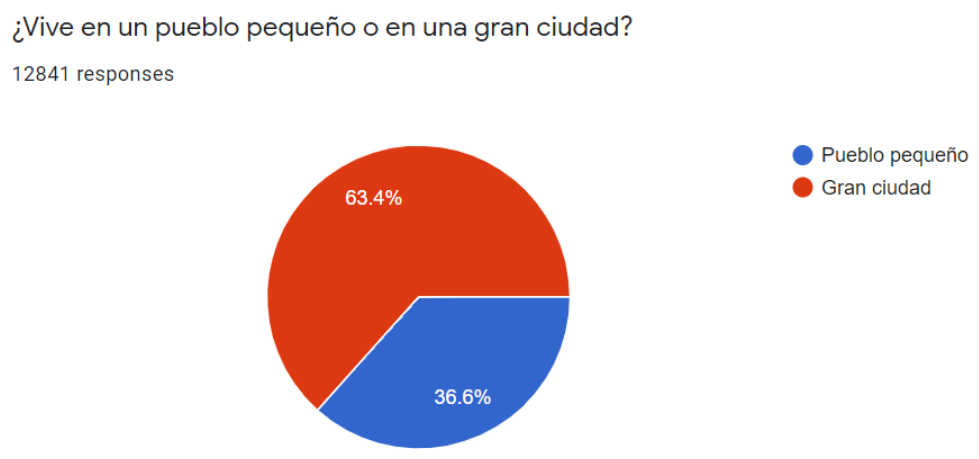

Figure 21. Second question of the survey

Most of respondents live in big cities, which implies there are valid reasons to have an UBER-like service to address the needs of as many customers as possible.

3-Do you think that, in general, the outreach of bank branches is limited? 
¿Cree que, en general, el alcance de las oficinas bancarias es limitado?

12841 responses

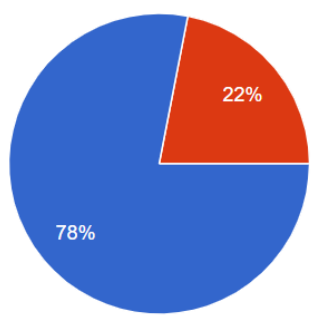

Figure 22. Third question of the survey

Most of our customers have limited access to bank branches, which confirms that with SantCar we will solve this problem by being able to get geographically closer to them.

4-Do bank opening hours normally pose a problem for you?

Normalmente, el horario de las oficinas bancarias ¿le supone una limitación?

12841 responses

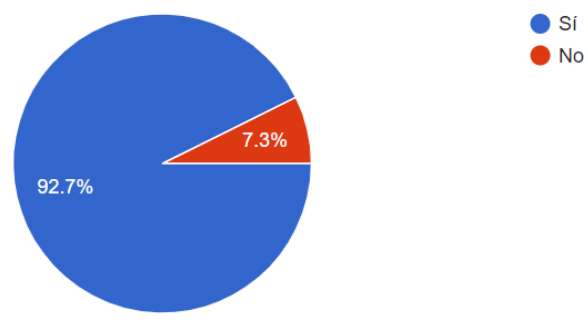

Figure 23. Ford question of the survey

As mentioned at the beginning of this article, the timetable poses a great difficulty for customers in general as their working hours coincide with the working hours of bank branches.

5-Do you currently consider that the range of services offered to manage your banking transactions is fully covered?

Actualmente ¿conisdera que se cubre completamente la oferta de servicios para la gestión

de sus trámites bancarios?

12841 responses

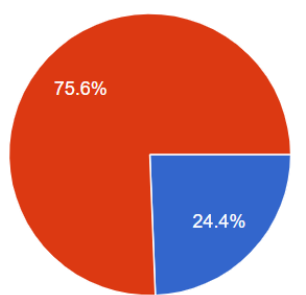

Sí, mayoritariamente

No, podria mejorarse

Figure 24. Fifth question of the survey 
- More accurate calculations of of maintenance costs.

- Calculations of time savings from banking through SantCar experienced by customers and employees

- Calculations of the exact payback period (PR) to recover the money invested in each SantCar.

\section{Payback Period}

In any project, a lot of importance is always given to the time needed to recover the money invested in a new business. After the closure of two Santander Bank branches, this period will be shorter, due to the savings in maintenance costs and employee salaries at those branches.

A former branch manager of a bank in Spain has been contacted and has confirmed the following:

- The monthly costs for an average office with four employees (personnel costs, operating costs and fixed costs) are approximately 25,000 euros.

- The installation of a new bank office, including the purchase of the premises (not rent), for four employees, dimensions of 200 meters squared, with taxes, computer equipment, two ATMs, security system and furniture is approximately 1.500 .000 euros.

Therefore, by proceeding with the temporary closure of the two offices chosen above, we could save at least 50,000 euros per month.

If we continue with the idea of temporary closure for three months we could recover the money invested in this project. This time mentioned is calculated without taking in consideration the profits of Santander Bank during these three months.

\section{Goal of 2031}

The following section presents a comparative analysis between the current situation and the desired situation in ten years.

\subsection{Current Situation}

Nowadays, what is measured in banking institutions is the efficiency ratio of an office, i.e. how much is earned for each euro invested. Serving customers does not give exact information on the productivity of an office or an employee because, for example, an employee could serve 100 customers but without any valuable sales, so no earnings would be registered.

The productivity of an employee increases as value of sales increases. By relating productivity to the efficiency ratio, we can conclude that an employee has to generate resources to pay their salary, the rest of the overheads and profit for the entity. If the fixed costs of the office are 25,000 euros, the 25,000 must be divided by the four employees and the working days of the month, i.e. 22 days on average, to which a minimum of $5 \%$ must be added as profit contributed by the employee. In other words, each 20\% Efficiency Ratio of a financial institution would be equivalent to 25,000 euros, and what is left over would be the Contribution Margin (net profits).

A former branch manager of a national bank in Spain has been contacted and stated that the Breakeven Point is obtained by reaching what was mentioned above, i.e. by reaching an efficiency ratio of $20 \%$.

For some time now, the policy of financial institutions has been that customers should operate through alternative distribution channels (basically, online banking and ATMs) and not through traditional channels, i.e. face-to-face banking in branches. If banks eliminate staff, they are reducing one of the biggest fixed costs they have to incur, which on the other hand increases their Efficiency Ratio. So what we see is the same business but with less costs and more profit. With SantCar, we can say that we can reduce these costs, and at the same time increase the productivity of our employees. All due to the mobility that is also more convenient for our customers.

According to Santander Bank's 2020 financial report, the average Efficiency Ratio reached 47\%. With SantCar we want to increase this ratio to $49 \%$ as our service will be further expanded, and we will reach a larger number of people to proceed with their banking transactions.

\subsection{Breakeven Point}

If we proceed to detail the expenses and revenues of each SantCar, we can arrive at the necessary Breakeven Point:

Efficiency Ratio $($ cash flow $)=(49 \% / 20 \%) * 25$ thousand $=61,250$ euros per month.

Variable expenses $=$ fuel costs + SantCar maintenance costs + employee salaries $=420+200+$ $(2500+1200+1200+1200+1700+1700)=8,920$ euros per month. 
Contribution margin $=$ input - variable expenses $=61,250-8,920=52,330$ euros per month.

Fixed costs $=$ start-up costs for each SantCar $=73,223.45$ euros "one-off".

First year net profit $=$ contribution margin $* 12$ - fixed costs $=52,330 * 12-73,223.45=554,736.55$ euros .

\subsection{Where Would We Be in 10 Years?}

The initial aim of launching SantCar is to solve the problems that our customers face, however, from a practical point of view, Santander Bank also wants to generate more profit by launching SantCar.

We currently have 1,814 branches in all provinces of Spain but in 2031 we want to reduce the number of these branches to $65 \%$, i.e. 1,180 branches. This would mean that we would have closed 634 branches, resulting in the following:

- Saving 15,850,000 euros per month on branch maintenance, assuming that all branches have an expense of 25,000 euros per month.

- If we proceed to sell each branch for 1 million euros (using more conservative estimates), we would be saving $634,000,000$ euros, and improve the cash flow of our bank.

- We will have about 500 SantCars in all the provinces of Spain, so each province will have about 10 SantCars, depending on the demands of the province.

Annual net profits earned from the 500 SantCars in $2031=$ Contribution margin of each SantCar * 12 months * 500 SantCars $=52,330 * 12 * 500=313,980,000$ euros per year.

Annual savings after closing the 634 branches $=15,850,000 * 12$ months $=190,200,000$ euros per year.

Sales proceeds from the sale of the 634 branches $=634,000,000$ euros.

The launch of the 500 SantCars will cost the following $=73,223.45$ euros (for each SantCar) $* 500=36,611,725$ euros as a one-off cost.

Using conservative estimates (not taking any profit calculations as indicated above into account), if we invest in the 500 SantCars using the proceeds of the sale of 634 branches, we would still have a cash flow of 597,388,275 euros.

In other words, if we follow this strategy, in 10 years we would have arrived at the following:

Saving 1,902,000,000 euros in variable expenses after closing the 634 branches.

Net profit from the 500 SantCars $=3,139,800,000$ euros.

\section{Conclusions}

Considering all that has been mentioned in the report, we can arrive at the following conclusions:

- SantCar will be able to solve most of the problems that our clients suffer from, mainly the working hours of our offices and the lack of banking service in remote villages.

- There is no competition in the current market, as no project similar to ours has been launched before.

- SantCar will be launched mainly in Madrid and in the villages of Aragon previously listed.

- The costs of designing SantCar and creating the mobile application are null.

- The total cost of this project is $152,686.9$ euros.

- The payback period of the project is three months, without taking into consideration the profits of this new project. In other words, in a case based on conservative calculations

- The payback period calculations take into consideration the maintenance costs of SantCar.

- Publicity of the SantCar service is necessary before launching it on the market.

- Our survey shows that current customer satisfaction is low and could be improved by our project.

- SantCar will have a positive acceptance at national level.

- The project phases need to be followed without delay.

- All risks that could arise during the test phase of SantCar have been identified.

- Santander Bank will cover most of SantCar's costs by temporarily closing some branches during the test phase.

- It will have closed around 634 branches by 2031, and once that is done, it will save around 190,200,000 euros per year in variable costs if we assume that each branch pays 25,000 euros in variable costs on average. 
- We will have launched 500 SantCars by 2031, and once that is done, we will have a profit of around 313,980,000 euros per year.

\section{References}

Alsamman Construction Group Company. (2021). Offer of the Security System mentioned above was from this company. Retrieved from https://www.sammangroup.com

Android Application Development. (2014). University of Alicante. Alicante-Spain.

Android Studio Developer Manual. (2016). La magia de las palabras. Juan Pablo Rodríguez Montoya. Gabriel Hernando Fuentes Amorocho. Retrieved from http://hdl.handle.net/10554/19569

Android Studio. (2020). Android Studio as a developer software. Retrieved from https://developer.android.com/studio

BBVA Bank. (2021). Official website of BBVA Bank. Retrieved from https://www.bbva.es/personas.html

CaixaBank. (2021). Official website of CaixaBank. Retrieved from https://www.caixabank.es/index_es.html

Caravans. (2019). Bürstner Ixeo Time it 734 G. 错误！超 链接引用无效。 Retrieved from https://www.comercialcaravaning.com/vehiculo/burstner-ixeo-time-734-td-segunda-mano/

Money Math for Teens. (2014). Assessment Solutions: Break-Even Point. FINRA Investor Education Foundation. Retrieved from https://www.saveandinvest.org/sites/saveandinvest/files/Break-Even-Point.pdf

Practical manual on programming in Visual Basic. (2016). Carlos Capellán. Comprehensive Training and Development Centre Padre Fantino. Dominican Republic.

Programming through examples. (2012). Palomo Durate. Department of Languages and Informatics System. University of Cadiz. Ildefonso Montero Pérez. Department of Languages and Informatics System. University of Cadiz. Cadiz-Spain. Retrieved from https://openlibra.com/es/book/programacion-en-php-a-traves-de-ejemplos

Sabadell Bank. (2021). Official website of Sabadell Bank. Retrieved from https://www.bancsabadell.com/cs/Satellite/SabAtl/Particulares/1191332204474/es/

Santander Bank. (2019). How many branches of Santander Bank in total are in Spain?. Retrieved from https://www.bancos.wiki/banco-santander/oficinas\#: :text=La\%20entidad\%20bancaria\%20Banco\%20Santande r, \%2C\%20Alicante\%2C\%20Asturias\%2C\%20etc

Santander Bank. (2020). Efficiency Rate. Financial Report. Retrieved from https://www.santander.com/content/dam/santander-com/es/documentos/resultados-trimestrales/2020/4t/rt-4t-20 20-informe-financiero-es.pdf

Santander Bank. (2021). How many braches do we have? A website, which indicates the number of branches in each place. Retrieved from https://www.bancosantander.es/buscador-oficinas-cajeros

Santander Bank. (2021). Official website of Santander Bank. Retrieved from https://www.bancosantander.es/particulares

Santander Bank. (2021). Opening hours of Santander Branches. Retrieved from https://www.bancosantander.es/horario-oficina\#: : :text=Lunes\%20a\%20jueves\%3A\%208\%3A30,30\%20a\%201 4\%3A30\%20h.\&text=atenci\%C3\%B3n\%20en\%20caja,Clientes\%3A\%20lunes\%20a\%20viernes\%20de\%208\% $3 \mathrm{~A} 30 \% 20 \mathrm{a} \% 2011 \% 3 \mathrm{~A}, 00 \% 20 \mathrm{a} \% 2010 \% 3 \mathrm{~A} 30 \% 20 \mathrm{~h}$

SolidWorks. (2021). SolidWorks as a software for designing SantCar plans. Retrieved from https://www.solidworks.com/sw/support/downloads.htm

\section{Copyrights}

Copyright for this article is retained by the author(s), with first publication rights granted to the journal.

This is an open-access article distributed under the terms and conditions of the Creative Commons Attribution license (http://creativecommons.org/licenses/by/4.0/). 